\title{
XLV. Note on Hall's phenomenon
}

\section{Herbert Tomlinson B.A.}

To cite this article: Herbert Tomlinson B.A. (1884) XLV. Note on Hall's phenomenon, Philosophical Magazine Series 5, 17:107, 400-402, DOI: 10.1080/14786448408627532

To link to this article: http://dx.doi.org/10.1080/14786448408627532

曲 Published online: 29 Apr 2009.

Submit your article to this journal

Џ Article views: 2

Q View related articles $₫$ 
crosspiece of wood M, M, and are insulated from the tongues by india-rubber.

A quadruple crank, $Q$, is arranged to be rotated between the supports of the crosspiece $M, M$ by means of the handle $H$. The crank is put under the tongues at the points where they are pressed by the springs. By rotating this crank four alternate plungers (I, III, V, VII) are lifted ont of their mercury-cups, the other four (II, IV, VI, VIII) being pressed in by the springs; or, on turning the crank through $180^{\circ}$, the four tongues (II, IV, VI, VIIII) are lifted out and the other four pressed into contact by their springs.

The electrodes of the resistances to be compared are introduced into the mercury-cups $\alpha, \beta$ and $\gamma, \delta$ respectively, or they could be soldered to continuations of the tongues with which these cups are connected.

Thus rotating the crank determines one of the following series of connexions:-

1st position. Contacts..... 1 I. 3 III. 5 V. $7 \mathrm{VII}$. Connexions A $\alpha . \quad \mathrm{B} \beta . \quad \mathrm{C} \%$. D $\delta$.

2nd position. Contacts.....2 II. 4 IV. 6 VI. 8 VIII. Connexions A $\delta$. B $\gamma$. C $\beta$. D $\alpha$.

So that the coils $\mathrm{X}$ and $\mathrm{Y}$ are alternately connected with $\mathrm{A} B$ and $\mathrm{C} \mathrm{D}$, and vice versâ, by a half-rotation of the crank.

It is necessary that any method of interchanging the coils should not alter the resistance of the connexions. It will be seen that the arrangement described is quite symmetrical, and therefore satisfactory in this respect, except for the piece of copper connecting I, II with $\delta$; and the resistance of this, if the copper be fairly thick, is too small to be appreciable.

Cavendish Laboratory, Cambridge,

March 7, 1884.

\section{Note on Hall's Phenomenon. By Herbert Tomlinson, B.A.*}

TN a paper entitled "The Influence of Stress and Strain on the Action of Physical Forces" $\uparrow$, I drew attention to the fact that there is a marked resemblance between the table of "rotational coefficients" drawn up Prof. Hall and that laid down by myself from the results of experiments on the effects

* Communicated by the Physical Society. Read March 22, 1884.

$\dagger$ Phil. Trans. Part I. 1883, p. 168. 
of mechanical stress on the specific electrical resistance of metals. A comparison of the two tables given below shows that, with the exception of platinum, the metals stand in nearly the same order in both, and that iron and nickel are very conspicuous, the one at the top and the other at the bottom of the lists. The last-named metal is especially worthy of notice, because in it longitudinal traction, when not carried beyond a certain limit, diminishes the electrical resistance in spite of the increase of length and diminution of section which ensues.

\begin{tabular}{|c|c|c|}
\hline Name of Metal. & $\begin{array}{l}\text { Rotational } \\
\text { coefficient*. }\end{array}$ & $\begin{array}{l}\text { Temporary alteration } \\
\text { of specific resistance } \\
\text { per unit produced by } \\
\text { temporary inerease of } \\
\text { length per unit. } \\
+ \text { signifies increase of } \\
\text { resistance on applica- } \\
\text { tion of stress. }\end{array}$ \\
\hline 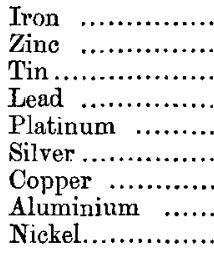 & $\begin{array}{l}+78.0 \\
+150 \\
-\quad 0.2 \\
\quad 0 \\
-\quad 2.4 \\
-\quad 8 \cdot 6 \\
-100 \\
-50.0 \\
-1200\end{array}$ & $\begin{array}{l}+2 \cdot 618 \\
+2 \cdot 113 \\
+1 \cdot 630 \\
+1 \cdot 613 \\
+2.239 \\
+1 \cdot 617 \\
+1 \cdot 005 \\
-0.420 \\
-8.860\end{array}$ \\
\hline
\end{tabular}

It might then be suspected that the results obtained by Hall are capable of receiving an explanation, in the fact that the electrical resistance of the strips of metal used by him would be altered by the mechanical strain consequent on their endeavour to move across the lines of magnetic force. Mr. Shelford Bidwell has, however, in his recent interesting communications to the Royal Society and the Physical Society, pointed ont that "Haill's phenomenon" cannot be thus accounted for. Nevertheless, as it seems not improbable that there is some indirect connexion between the alteration of electrical resistance produced by mechanical stress and the "Hall effect," I have little doubt but that experiments on the "rotational coefficient" of nickel, in which the temperature is varied up to $100^{\circ} \mathrm{C}$, or in which the strips are subjected

* A + sign attached to a metal signifies that the effect is in a direction the same as that which the conductor itself bearing the current would follow if free to move across the lines of magnetic force under the action of the ordinary "ponderomotive" force. 
to mechanical traction of varied amount, would assist in deciding the question as to whether purely mechanical stresses are to be regarded as producing the phenomenon. For it has been shown* that with this metal the maximum diminution of resistance following from longitudinal traction is at $100^{\circ} \mathrm{C}$. less than one half of that at $15^{\circ}$; and, further ${ }^{\prime}$, that whilst traction not exceeding a certain limit produces diminution of resistance, increase of stress beyond this limit is followed by increase of resistance. Hall has remarked, in the 'Philosophical Magazine' for September 1881, that the transverse current obtained with a nickel strip is much increased, other conditions remaining unchanged, by rise of temperature. But his experiments in this direction are, I think, hardly conclusive; and, indeed, an examination of the numbers given in the column in which the values of the "rotational coefficient" are recorded shows, in the first ten out of the eighteen experiments, evidence that rise of temperature causes a decrease of the transverse current. Should Hall's phenomenon prove to result from mechanical strain, I incline to the belief that a rise of temperature from $15^{\circ}$ to $100^{\circ} \mathrm{C}$. will produce decrease in the transverse current.

The experiments of Mr. Bidwell tend very largely to prove that the "Hall effect" can be explained by the joint action of mechanical strain and certain "Peltier effects." Should this be so, we ought, I think, to be able, by means of two thermoelements connected with each other and with a delicate galvanometer, one element being in a cooled region and the other in a heated region, to put this theory to the test. Or, again, we might cover the strip with some material of bad thermal conductivity and watch for a gradual increase of transverse current with time when the electromagnet is excited, and gradual decrease when the electromagnetic stress is removed. Indeed in the actual arrangement adopted by Hall and Bidwell, it would seem that this gradual increase or decrease should occur ; for though the strips themselves would rapidly cool if unmounted and exposed to the air, the nonconducting material of the mounting would take some little time both to gain and lose the heat imparted to it by the strip.

$$
\text { * Loc. cit. p. } 125 . \quad+\text { Loc. cit. }
$$

